\title{
La Estructura de la Novela de Juan Carlos Onetti: Juntacadáveres
}

He dividido el estudio de esta novela en: I) Estructura Interna, y II) Estructura Externa, cubriendo en la primera el estudio del tiempo y del desarrollo de la acción y en la segunda los temas de esta acción. Al final de la primera parie se estudian separadamente las técnicas narrativas de Onetti y se dedica una sección especial al Capítulo XII. Al final de la segunda parte también se dedica una sección separada para el último capítulo.

Este estudio será iniciado con un examen del desarrollo de la acción de esta novela en la cual la secuencia temporal ha sido organizada de acuerdo a un orden estético que resulta en un mayor valor artístico y en un mayor interés para el lector que el de la simple secuencia cronológica de los acontecimientos.

En el caso de Junibadáveres, publicada en 1964, el tiempo está ordenado de acuerdo con la necesidad de narrar eventos que tienen lugar en algo más de tres meses; sin embargo hay años y vidas enteras comprimidas dentro del otro tiempo que se limita a la acción con que comienza y termina la novela.

Entre las primeras preguntas que se formula a sí mismo el lector de esta novela de Oneiti, se cuenta la siguiente: ¿Cuál es el objeto de esa gimnasia novelística que altera el tiempo cronológico de los hechos relatados? Una sola contestación no bastaría para agotar esta pregunta, pero aún el lector menos avezado no dejaria de observar que la novela se inicia con la llegada al pueblo de Santa María del núcleo de personajes que instalarán el lenocinio y que la novela concluye con la partida obli. gada del mismo grupo. Hay aquí, si no una vuelta al punto de partida de la novela, por lo menos un intento de indicar la simetría falsa o ver. 
dadera que pueden y suelen poseer los actos humanos. De este modo, la novela que comienza con una llegada y termina con una partida es epilogada con una muerte, la de Julita Malabia, cuyo capitulo final devuelve al lector a la normalidad. Así, Juntacadáveres es comparable a un organismo viviente cuyo acto inicial es la llegada a un mundo desconocido y cuyo acto final es una partida hacia lo desconocido que es también epílogo al que se llama muerte.

Esta comparación inicial contiene y explica a Juntacadáveres, porque como todo organismo tiene su razón de ser en sí mismo por ser un fenómeno único dentro del marco temporal de su comienzo y de su fin.

Retomando la pregunta inicial se comprueba que la gimnasia tem. poral de ir y volver en el tiempo aunque neutraliza el orden cronológico no lo destruye sino que lo acomoda al propósito estético. El tiempo dislocado de Juntacadáveres ameniza la acción proveyéndola de descansos adecuados. Asi cronológicamente el Capitulo IX, que narra los hechos de la vida de Larsen, alias Junta, alias Juntacadáveres, corresponde a un tiempo en que éste vivía en Rosario y es, además, una incursión al pasado de este personaje. Como un salto atrás en el tiempo, el Capítulo XXII complementa al IX y en él se llega al conocimiento del origen del apodo de Larsen:

Había que vivir y por eso, inventó el patronazgo de las putas pobres, viejas, consumidas, desdeñadas. (p. 183) ${ }^{1}$

El tratamiento del tiempo por Onetti tiende a agrandar el ámbito de la acción, porque cada visión retrospectiva avanza en el pasado como series de círculos concéntricos que amenazan desbordar los límites de la acción o acciones principales de la novela. Esto se aprecia con cla. ridad en uno de los últimos capítulos del libro, el que lleva el número XXX (pp. 232.238), porque en él el narrador nos proporciona la historia de Villa Petrus, sus hoteles, sus casitas, su función social, todo lo cual incide poco o nada en la novela. La conclusión es que el tiempo de Juntacadáveres es un tiempo de metástasis, va cambiando de lugar, un tiempo que añade a cada paso personajes y circunstancias que son nuevos para el lector. Sin dificultad puede concebirse esta novela como perteneciendo al tipo de novela 'en la que los episodios se multiplicarían incesantemente como ondas concéntricas. Esta concepción está confirmada por la comparación de Juntacadáveres con algunas de las otras no.

1 Juan Carlos Onetti, Juntacadáveres (Montevideo, Uruguay: 1966). Todos los números de páginas que aparecen en el texto corresponden a este volumen. 
velas de Onetti, especialmente con El Astillero. Luis Harss, en su libro Los Nuestros, comentando sobre este aspecto de la obra de Onetti, afirma acertadamente que éste es "protagonista de un libro inconcluso que ha venido escribiendo hace años", 2

En esta forma se aborda la estructura interna de Juntacadáveres, cuya acción se desarrolla dentro de este tiempo circular mencionado antes. Este aspecto de toda la obra de Onetti también lo menciona Luis Harss en el libro antes citado:

Onetti es partidario de lo circular y lo estático, recursos perfectamente legítimos en un mundo de destinos fijados de antemano, en el que cada vida es una condena retroactiva, predestinada $y$, por lo tanto, en cierto modo tautológica. ${ }^{3}$

Se puede aceptar que Onetti sea partidario de lo circular en el orden estético de las cosas, pero no así en el orden vital como lo afirma Luis Harss al referirse al mundo de Onetti como un orbe en que cada vida está predestinada. El destino de los personajes de Onetti responde al arbitrio de su creador que es Onetti mismo, y al hacer Luis Harss su afirmación confunde la ficción con el mundo real.

$\mathrm{La}$ acción de Juntacadaveres comienza un "primer lunes de las vacaciones" (p. 10) y termina alrededor de "en vísperas de carnaval" (p. 247) con una referencia adicional y oblicua de Lanza a la duración total: "Pero algún día publicaré la historia de estos cien días que conmovieron al mundo" (p. 249). Así, con una ligera impresión irónica, Lanza confirma la duración de la acción.

Sin embargo, hay también otra clase de tiempo en Juntacadáveres, el tiempo subjetivo de sus personajes, que está más ligado a la estructura de la frase de Onetti que a la del tiempo de su novela. Este tiempo sicológico es lento, de un torpor estival de sangre inflamada, de letargo y lujuria premeditada, sin violencias ni paroxismos, salvo contadas excepciones. A este respecto, Luis Harss nos dice algo que ya sospechába. mos: "Onetti lleva a cuestas a un maestro que ha tenido sobre él una enorme influencia: Faulkner". "Esas largas oraciones tan contorsionadas de Onetti, como las llama Luis Harss, que a veces caen en el firulete, son las responsables del progreso a lo cortejo fúnebre característico de Juntacadáveres.

\footnotetext{
2 Luis Harss, Los Nuestros (Buenos Aires: 1968).

3 Harss, p. 237.

4 Harss, p. 237.
} 
Vamos a examinar ahora algunos de los recursos técnicos de que se sirve Onetti para controlar el tiempo en esta novela. Una manera de integrar el pasado con el presente es mediante la utilización del "flashback". Esta mirada retrospectiva tiene lugar en algunos casos cuando el narra. dor omnisciente, como es el caso en el Capítulo III, se introduce en un personaje, el Dr. Díaz Grey en este caso, y nos dice cómo este último rememora situaciones pretéritas reproduciendo diálogos o fragmentos de los mismos. O'ras veces, como en el Capítulo IV (p. 26), el narrador omnisciente deja hablar a su personaje, en este caso también el Dr. Díaz Grey, poniéndonos en contacto no ya con la experiencia vivida, o sea con el recuerdo de hechos pasados, sino con la intimidad del personaje al que obliga de este modo a monologar consigo mismo, monólogo interior dirigido al lector. Piensa Díaz Grey a propósito del boticario Barthé:

Nació aquí, en la costa... No es una persona; es como todos los habitantes de esta franja del río, una determinada intensidad de existencia que ocupa, se envasa en la forma de su particular mania, su particular idiotez. Porque sólo nos diferenciamos por el tipo de autonegación que hemos elegido o nos fue impuesto. (pp. 26-27).

El método que utiliza Onetti sirve para mostrar a un segundo personaje, el boticario Barthé, viśo a través de la particular actitud vital del primero. Este pasaje es adenás interesante porque ilumina al primer persosonaje y también porque sin transición aparente expone las ideas del narrador omnisciente. El Dr. Díaz Grey queda convertido momentánea. mente en portavoz de Onetti. $Y$ entonces es One ti quien afirma que la autonegación que elegimos o que nos fue impuesta es lo que sirve para diferenciarnos. Admite Onetti entonces la libertad del ser humano a aceptar o a rechazar algo, aunque más no sea como una autonegación. Esto es justamente lo que le habiamos objetado a Luis Harss cuando afirmaba que Onet i concebía cada vida como una condena retroactiva y predestinada. El narrador omnisciente, a través de Díaz Grey, en este pasaje no niega la posibilidad de la contingencia de los actos humanos. Aunque como dice Díaz Grey para aclarar lo de la autonegación:

$\mathrm{Y}$ así también este pobre hombre, al que me empeño en querer, dejó de ser el auténtico y para siempre ignorado Euclides Bar:hé hace muchos años; y todos, sin desconfianza, lo ven representar el boticario, el herborista, el concejal y -ahora hasta su muerte- el profe a de los postíbulos sanmarianos. (p. 27). 
La mala fe de Barthé, su particular modo de autonegación, es ignorar su propia autenticidad y como todos los sanmarianos se conducen en igual forma, todos pueden mirar a Barthé sin desconfianza. Barthé ha renunciado, hasta su muerte, su au'enticidad, es decir el saberse individuo humano mortal e insignificante, la calidad esencial de la condición humana. Este tema está concebido en Juntacadáveres como principio que gobierna toda la exposición de la acción. La trama gira en torno a la autenticidad de sus personajes. Algunos como Jorge, Federico, Julita y aún Larsen son auténticos o buscan serlo; otros se han entregado a la mala fe de creer ser la personalidad que proyectan, como lo señala Díaz Grey al hablar del bóicario Barthé. Será necesario volver sobre este punto oportunamente.

Retornando a las visiones retrospectivas, en cuanto al empleo de técnicas, Onetti hace hablar a un personaje en el curso de un diálogo y le fuerza a narrar su pasado. Tal es el caso de Larsen cuando hablando con Díaz Grey dice: "Vine porque Barthé me mandó llamar. Yo estaba en el Rosario y, créame, estaba bien" (p. 47). Sin pretender hacer un catálogo de las diferentes técnicas empleadas por Onet i para manejar el tiempo sino solamente para destacar algunas de ellas y llamar la atención sobre la importancia que tienen para la estructura de esta novela, estudiaremos ahora el Capítulo XII, que es uno de los más complejos y que en esta novela es la secuela temporal del Capítulo V y del VII. El diálogo multidimensional de Oneiti: El Capítulo XII ofrece un ejem: plo bien acabado de la complejidad del diálogo de Onetti. Se inicia con ia voz de Lanza en primera persona en un "flashback" hacia su propia adolescencia. Con este principio se logra desconectar al lector haciéndole suponer que el punto de vista narrativo ha cambiado una vez más, pero no es así. El narrador en primera persona sigue siendo Jorge Malabia y el lector puede observar que intercalados en las alternativas del diálogo aparecen pensamientos de Jorge que son: 1) íntimos; 2) que no llegan a ser formulados más que como pensamientos pasajeros; 3 ) que interfieren con la secuencia del diálogo y que incluso 4) afloran involuntariamente, indicando así que 5) perienecen a varios niveles de la conciencia. Este diálogo entre Lanza y Jorge es entonces multidimen. sional porque, en conclusión, permite valorar a ambos personajes desde adentro y desde fuera, desde el presente y también desde el pasado, simultáneamente. Lo descriptivo y lo narrativo se alternan sin más orden ni lógica que la que tiene el foco de la conciencia al ir pasando de un objeto a otro. Esto explica algunos de los pasajes en que Jorge describe sus movimien'os más superfluos. Comprobemos ahora todo esto con 
ejemplos. Al comenzar el capítulo, cuando Lanza habla, tenemos el siguiente pasaje:

.. hasta las orejas - dice Lanza; respira con la boca y la deja abierta para que yo vea que sonríe, cuántos dientes le faltan y cómo manchó el tabaco los que quedan; me molesta, nadie tiene derecho a estar tan viejo-. Tal vez con menos sal, la boina... (p. 100).

La descripción de Lanza con su boca abierta, sonrisa y correspondientes dientes manchados, la observa Jorge junto con el introspectivo y yuxta. puesto "me molesta. .." que se aparta ya de Lanza y arroja a Jorge a un autoanálisis brevísimo que recupera la visión de la vejez de Lanza acto seguido. Todo esto ocurre en la conciencia de Jorge durante la pausa momentánea que hace Lanza entre su ". . hasta las orejas" y su "Tal vez..." abruptísimo este último para el lector.

La atención de Jorge conduciendo el fluir de su conciencia lleva a esta última a algunas descripciones sucintas y superfluas que aparecen en el texto en un intento de mostrar cómo lo marginal interviene y se intercala aumentando o disminuyendo la intensidad del foco de conciencia o ya, pasando de lo puramente intelectual a lo afectivo:

Alzo la jarra... El nazi, atrás del mostrador, se rasca una axila y conversa con el mozo; miran hacia mi mesa. (p. 101).

Abruptamente la inseguridad del adolescente aflora luego del último "miran hacia mi mesa" y la conciencia de Jorge tegistra lo siguiente: "Entraron mujeres, tal vez quieren pedirme que me quite la boina" (p. 101). Luego prosigue Jorge con el mismo movimiento de vaivén entre lo externo y lo íntimo: "Junta Cadáveres está sentado en el fondo con el tipo de la distribución de los diarios. No me voy a quitar la boina; le voy a decir al patrón... (p. 101). En el pasaje precedente se comprueba cómo lo afectivo profundo cede el paso al impulso de lo volitivo y premeditado, presentándosenos articuladamente otra nueva modalidad de la conciencia: lo volitivo pensado y formulado mentalmente seguido de un corolario lógico: "... que si Junta Cadáveres puede poner los pies en el Berna también yo puedo estar".

Lo que falta aquí es un eslabón lógico que quedó sin formular. La conciencia de Jorge ha dado por sentado algo que no pasó de ser una imagen fugaz. Reconstruyámoslo hipotéticamente como lo que podría haber sido: "No me voy a quilar la boina"; (si me piden que abandone 
el local) "le voy a decir al patrón que si Junta Cadáveres puede poner los pies en el Berna también yo puedo estar".

En su inseguridad de adolescente, Jorge adopta una actitud automática de desafío: no quitarse la boina. Fugazmente concibe una imagen del patrón conminándole a descubrirse o a hacer abandono del local. Inmediatamente surge una actitud de defensa y justificación de su derecho a quedarse por no ser él menos que Junta Cadáveres. Res'ablecido precariamente el equilibrio emocional, la conciencia de Jorge sigue narrando dentro del diálogo con Lanza: "Llamo al mozo y pido más cerveza, un paquete de cigarrillos. Julita me puso cien pesos en la mano..."

En una yuxtaposición violenta para el lector, pero normal y enteramente habitual para la conciencia en acción, Jorge nos lleva de los ci. garrillos a un "flashback" que nos retrotrae a su encuentro con Julita esa misma noche antes de su conversación con Lanza. El fin de este "flashback" es también abrupto; sin mediar transición alguna la aten. ción de Jorge se vuelve hacia su interlocutor: "bajó hasta la puerta del jardín, me besó en la boca mientras metía el billete en mi puño y me empujó hacia afuera. Dijo algo antes de cerrar. Lanza me vio mirar a Junta..."

Será necesario que en el proceso de la lectura el lector siga las alternativas de este fragmentarismo durante otras tres páginas para poder recién saber qué fue lo que dijo Julita a Jorge antes de cerrar.

El Capítulo XII es, a nuestro criterio, el mejor de toda la novela porque presenta una cantidad de refinamientos técnicos con los que Onetti busca superarse en un intento de combinar las técnicas literarias con las cinematográficas. En los pasajes que hemos discutido al tratar de este capítu'o, hemos mostrado cómo Onetti combina la técnica del monólogo interior directo con desaparición de autor con la técnica del montaje en el tiempo y la del montaje en el espacio. En realidad, Onetti no consigue en ningún momento inmovilizar al tiempo en beneficio del espacio pero lo que sí consigue es dar al pasaje una atmósfera de tiempo detenido al hacer que el foco de la conciencia vaya pasando de una descripción a la siguiente en intervalos sumamente breves. Onetti no ha detenido al tiempo pero sí lo ha retardado hasta que los instantes se hacen larguísimos. Como consecuencia de este procedimiento la prosa de One'ti ha sufrido y esto ha llevado a Luis Harss a afirmar que hablar del estilo de Onetti es tratar un tema penoso y que a veces su estilo es insufriblemente elíptico. Tal vez esto sea tal como lo afirma Luis Harss, pero es también indudable que este estilo gana en calidad con las complejidades técnicas que hemos señalado presentes en él. 
El Capitulo XIV ofrece otra técnica diferen e del manejo del tiem. po. En él se narra retrospectivamente el empleo que Larsen hace en la capital de sus diez días de licencia sin goce de sueldo que ya habían sido mencionados anteriormente en el Capítulo VIII. Esta manera de presentar una acción constituye una vuelta a un tiempo anterior al del comienzo de la novela en su Capítulo I. Lo interesanie es que dentro de este "flashback" que es todo el Capítulo XIV se halla otro "flashback" cuyo objeto es explicar en qué época, forma y circuns'ancia Larsen llegó a ser proxeneta.

Dentro de la estructura interna de Juniacadaveres se hace necesario señalar el paralelismo irregularmente alternado a través de sus capítulos de dos series de acciones que, como tra aremos de probar, si bien contrastan entre sí, también se integran y se complementan una con otra. Juntucadedveres es la historia de dos crisis que ocupan el tiempo mencionado por Lanza al cual ya nos hemos referido: "estos cien días que conmovieron al mundo". Una de estas crisis, la que afecta a la comunidad de Santa Maria, es al fin y al cabo ilusoria si así se quiere, ya que Santa María con su colonia, su villa Petrus, su fábrica de conservas y su precario prostíbulo es una y la misma, an'es, durante y después de su crisis. Ya dijimos que esta crisis tiene por motivo central la autenticidad, pero es también una historia de mediocridad e hipocresía. Esto condice con la afirmación que hacemos ahora de que el lenocinio, Larsen, y las tres sacerdotisas profesionales del amor son factores accesorios para la crisis de la comunidad de Santa María pero no para la novela; y esto porque los elementos mencionados tienen función esencial cuando se trata de medir la impor ancia de la crisis para la comunidad y también porque ellos confieren dimensión a las acciones humanas. Así dice al respecto el crítico Luis Harss: "aquellos que luchan, aún en vano, contra el orden de las cosas, son al menos dignos de un piadoso respeto. Tal es el caso del abominable Larsen". ". Con esto Luis Harss nos dice que Larsen lucha en vano contra el "orden de las cosas" en Santa María y por lo tanto no afecta el "orden de las cosas" que es lo que constituye la crisis. El mundo de Santa Maria es un mundo anémico y falseado por los sanmarianos mismos que no se pueden ver tal cual son porque se han convertido y se han identificado con las imágenes que proyectan en su tiempo vital, en su circuns'ancia. Las crisis entonces están ligadas al tema de la auten-

5 Harss, p. 248. 
ticidad ya introducido anteriormente al discutir a Díaz Grey y al boticario Barthé.

Resumiendo un poco, se puede afirmar que en Juntacadaveres hay dos series de acontecimientos principales y paralelas: 1) crisis de una comunidad, Santa María; 2) la crisis JorgetJulita. Además de esto hay un catalizador pasivo constituido por Larsen y las tres mujeres.

La primera crisis, la de la comunidad, es estática porque no progresa y tenemos la evidencia de esto en la novela misma porque el estado de cosas en Santa María es el mismo antes, durante y después de la desaparición del prostíbulo. Todo el esfuerzo comunitario de la cruzada moralizadora va dirigido a proteger algo que no existe sino en la imaginación de los habitantes de Santa María. Ese algo es la salud espiritual que están lejos de poseer. Sin embargo, Santa María vive feliz con este estado decadente de cosas porque a pesar de ello la comunidad posee una estabilidad que, real o imaginada, puede ofrecer un respaldo cómodo cuan. do se hace necesario justificar la existencia del sistema en que se apoya la vida de la comunidad. El prostíbulo es pues una amenaza tanto más cierta por cuanto, si la comunidad está realmente podrida por dentro, su colapso será mucho más rápido y evidente. Que la comunidad de Santa María está podrida queda probado ante la imposibilidad de neutralizar la influencia del prostíbulo que desaparece bajo la influencia de factores ajenos a la comunidad: la orden del gobernador. No olvidemos que fueron los jerarcas de la comunidad en representación de ésta quienes aúorizaron la instalación del prostíbulo. Por lo tanto, frente a la prueba de la crisis interna, Santa María termina por afirmar su respetabilidad y con este gesto deja limpia la fachada del edificio social relegando la podredumbre moral a un interior en donde, por ser un mal general, se convierte en los altos principios de la comunidad.

Paradójicamente entonces, el prostíbulo, que normalmente es una im. perfección social aparece en esta novela como un instrumento de redención que podría servir para probar la resistencia a la debilidad de la carne. Todo valor para estar probado debe aparecer como triunfando sobre una cierta cantidad de oposición negativa. Con la expulsión del prostíbulo, Santa María arroja fuera del seno de la comunidad su única oportunidad de sanear los espíritus. Es por esto que hemos preferido señalar al prostíbulo y a los personajes que viven en él como elementos catalizadores dentro de la estructura interna de Juntacadáveres.

La segunda crisis, llamada de Jorge-Julita, es por naturaleza una anti-crisis que se origina en el anti-conformismo de Jorge Malabia y de Julita Bergner. El anti-conformismo de Jorge y Julita nace de un impera- 
tivo de autenticidad que, realizado o no, se opone a la inautenticidad, léase hipocresía, de la comunidad sanmariana. La locura de Julita puede ser definida como de enajenación por distanciamiento, y también la de Jorge, aunque exteriormente en éste tenga una diferente manifestación. En apariencia la locura de Julita data de la fecha de la muerte de Federico el que, según sabemos, muere a resultancia de una pulmonía con. traída luego de una caída de un caballo. Pero ésta no es la realidad. Realmente el mal de Julita es anterior a la muerte de Federico y encuentra su justificación en algo mucho más radical que la simple viudez de una mujer recién casada. Esto viene confirmado en la novela por Marcos Bergner cuando le dice a Jorge Malabia: "Está loca, Loca desde siempre. Lo tengo observado. Ya exa rara antes de la viudez, desde an'es de conocer a tu hermano" (p. 215). También Antón Bergner tenía conocimiento de esta situación y así se lo dice a Marcos Bergner: "Esperar qué? Esperar a que Julita, sola y rodéada por ustedes termine aceptando para siempre la locura que eligió como refugio" (p. 230). La locura de Julita, ese desequilibrio tan normal que consiste en la desidentificación con el grupo comunitario, es del mismo tipo del que padece Jorge. Para sobrellevar la autenticidad interior, en pugna con un medio social al que ella no puede someterse ni adaptarse, Julita finge un tipo de locura más normal y Jorge, por su parte, escribe poemas y se autoestudia. Es por esto que en Jorge y Julita la crisis es progresiva y va dirigida a buscar salidas o escapes a la presión de la comunidad, o si se quiere, para decirlo de otro modo, es un fenómeno de evasión. Ni Jorge ni Julita quieren claudicar aceptando una falsa mediocridad que les viene impuesta desde afuera. Por lo tanto ni se amoldan ni conforman a los cánones sociales. Federico Malabia, el hermano mayor de Jorge, era también así y por esto mismo Jorge admira a su hermano aún después de muerto. Federico también había buscado la evasión como solución, igual que Julita, igual que Jorge, "cuando... dejó la administración del diario y dijo que quería casarse y trabajar en el campo" (p. 189). Federico se evade del mundo de su padre y accidentalmente la muerte le proporciona la forma final de la evasión. Para Julita la evasión existe en un género de locura aceptable para la comunidad y en último término el suicidio como epílogo y única solución. Para Jorge otro tipo de evasión: la afirmación de su unicidad inalienable y de su protesta: "Yo soy yo, este ser, este 'muchachito' de ellos, triste, distinto, tan inseguro y firme como ninguno de ellos podría sospechar; tan aparte y por encima de todos ellos. Yo soy éste al que miro vivir $\mathrm{y}$ hacer, con simpatía, sin exceso de amor; éste 
de la paciencia cortés e inagotable para cada una de las comedias tediosas y sin gracia en que ellos se empeñan en complicarse..." (p. 33).

Poco a poco, Jorge irá pasando de la evasión al desafío abierto cuando junto con Marcos se instale en el prostíbulo. También Julita en crisis dinámica eligirá la muerte como liberación.

Si cediendo a la búsqueda de causas y efectos se intentara determinar cuál es el factor decisivo en el suicidio de Julita, éste se encontraría en la disyuntiva que tiene entre convertirse en una de las muchachas de la Acción o persistir en su fingida locura. Frente a esta interpretación tiene nuevo sentido la confesión de Jorge en el último capítulo: "Desde tanto tiempo atrás, ahora inmensurable, desde la muerte de mi hermano, sabíamos que Julita estaba muerta" (p, 253). Claro que Julita estaba muerta, era previsible. Julita había muerto con Federico pues junto con éste tenía su grupo comunitario. La reconstitución de la comunidad espiritual con Jorge es precaria y efímera para Julita. Esta vive entonces un tiempo gratuito en el tiempo de la novela, en "esos cien días que conmovieron al mundo", su leit motiv. Como ser auténtico, Julita muere y su muerte ratifica la muerte perpetua de la comunidad sanmariana. $Y$ al morit Julita por lo tanto quedan vinculadas estas dos crisis paralelas de la novela que ya señalamos. La comunidad sanmariana también está muerta y su redención por medio de la expulsión del grupo prostibulario sólo es un rito, una forma vacía, una catharsis que salvaguarda la mediocridad espiritual de los directores de la comunidad y por ende de todos sus miembros. Entonces la función del proxeneta Larsen y sus oficiantes del amor es puramente catalizadora porque su presencia en Santa María no produce nada que se acerque a ser una acción o una reacción auténtica. La comunidad sanmariana funciona automáticamente y el mismo status quo autentifica su falsedad cuando se libra pasivamente del prostíbulo.

El prostíbulo de Santa María que se identifica para los sanmarianos con la invasión del mal, lo pecaminoso, está muy bien contrastado con la experiencia comunitaria de Marcos Bergner y su "falansterio". El relato que Lanza hace a Jorge sobre el "falansterio" permite al lector concluir que Marcos había realizado con su "falansterio" el sueño del prostíbulo propio. La comunidad de Santa María se niega a evaluar las acciones de Marcos Bergner por sus resultados y el "falansterio" cumple su misión corruptiva ante la indiferencia general. Esta indiferencia indica la pasividad ovejuna del rebaño de Antón Bergner R. P. y tío de Marcos. Larsen y sus tres mujeres sólo ofenden al pudor superficial, falso pudor de la comunidad, que nunca se sintió ofendida ante las fechorías de 
Marcos porque en realidad la comunidad de Santa María no tiene pudor. Para salvaguardar una apariencia de salud espiritual, la comunidad pone en marcha su campaña anti-prostibularia pero aún esta acción es una acción enmascarada porque los defensores del bien moral no proceden abiertamente, ocultándose bajo una campaña de anónimos. Sólo después de que llega la orden oficial de cerrar el establecimiento de Larsen, de parte del gobernador, es que los detractores del mal organizan su desfile casi carnavalesco portando públicamente la divisa "Queremos novios cas. tos y maridos sanos" (p. 245).

La procesión "revindicadora" ocurre casi en vísperas de Carnaval y éste queda iniciado con aquélla. En esta forma la pantomima procesional se patentiza con más fuerza para el lector.

Hemos discutido ya dentro de la estructura externa de esta novela algunos de los temas que dominan la acción: la mediocridad, la autenticidad, la buena fe y la mala fe, y la hipocresía ambiental. También de algunos personajes nos hemos ocupado oportunamente, $y$ ahora volvemos sobre este punto.

La volubilidad creativa que demuestra Onetti en Jumuacadáveres es fecunda y se aprecia en la cantidad y variedad de personajes así como también en la facilidad que éstos tienen para rodearse de una circunstancia de existencia. Hay apenas un solo personaje en esta novela que sin ser propiamente su protagonista es algo más importante que los demás, no tanto por su dimensión sicológica sino por la significación de sus actos. Este personaje es Jorge Malabia que en la búsqueda del ser auténtico, en su esfuerzo de ontologizarse se singulariza entre los demás. Contribuye a esta afirmación el hecho de que en muchos de los capítulos Jorge es el narrador en primera persona, aunque no parece que pueda ser él también el narrador-protagonista de la mayor parte de la obra y mucho menos el casual y esporádico narrador omnisciente de ciertos pasajes. Pero por las razones enumeradas, Jorge tiene más importancia que su cuñada Julita. Nos parece acertada la elección de Jorge como cuasihéroe, pero hay que decir que esto no es una novedad en la historia de la novela. Lo principal en Jorge es su incontaminación y además el hecho de que con él se cumple una vez más la ley de que los más grandes zinemigos de los valores burgueses nacen y se educan en el seno de este sector social.

En páginas anteriores nos hemos ocupado de Julita y algo también de Federico, que sin aparecer como personaje, se da como una fuerza motivadora. Federico es parte del dinamismo histórico de la acción de la novela. 
Con cierto enfoque particular nos animaríamos a proponer que los personajes de Onetti en Juntacadáveres son personajes-islas, cuyo aislamiento no es tan feroz como el de algunos de los de Eduardo Mallea. Así Lanza, Larsen, o Díaz Grey, o Barthé, son existencias encapsuladas. Barthé sobre todo adquiere una descarnada dimensión por el ensañamiento con que Onetti lo va destruyendo a través de su novela cuando nos dice que Barthé es:

gordo y horizontal, con blanduras femeninas que rodeaban y suavizaban la cabeza calva en reposo, próximo a la respiración del muchacho empleado. (p. 17).

...su voz aguda y acariciante... (p. 18).

Con su voz de matrona y... con los carnosos dedos sin vello. (p. 25).

Debe ser eunuco... (p. 27).

Ciertas escenas y capítulos de Juntacadáveres son centros de irradiación que confieren dimensión a los personajes. Así el Capítulo XXIX se ocupa de la entrevista entre Antón Bergner y su sobrino Marcos. El di. rector y responsable de almas y su disipado sobrino alcanzan un perfecto acuerdo en una entrevista que no pasa de ser un convenio entre caballeros. Antón Bergner actúa entre telones y todas sus apariciones son teatrales. En cada una de ellas busca un efecto dramático o se asoma a recoger la aprobación pública. Antón Bergner confirma la teoría de Díaz Grey cuando llegamos a entender que aquél es otro tipo de auto negación cuyo pasatiempo consiste en creer ser el cura que representa. Nos deja convencidos de su inautenticidad.

En cuanto a Larsen, creemos que es un ser auténtico pero degradado, y también estéticamente para la novela un personaje que lleva el contrapunto con el cura Bergner. El dilema que zanja la distancia entre ambos personajes es el que plantea la disyuntiva que media entre prostituir almas o prostituir cuerpos. Larsen es una situación existencial limítrofe porque está entre la vida y la muerte. Su edad y la de los cadáveres que prohija los pone a todos al borde de la vida, pero aún así su autenticidad los salva de la mediocridad, pues no dicotomizan su existencia como Barthé, como Diaz Grey, o como el padre de Jorge.

El padre de Jorge es otro personaje falso. Su hijo Jorge lo sabe y, haciendo una transferencia de afectos, adopta secretamente a Lanza, el corrector de galeras de El Liberal como padre auténtico. De hecho, Lanza lo es porque le presta su sinceridad a Jorge tratando de inspirarle la se- 
guridad que su propio padre no sabe ni puede proporcionarle. Jorge mismo afirma esto de Lanza en el Capítulo XII cuando dice: "Lo quiero sin ternura, $\mathrm{y}$ hasta los vidrios sucios de sus anteojos, las bocamangas comidas, la corbata grasienta me sirven para respetarlo infinitamente más que a mi padre" (p. 101). En este pasaje observamos la combinación característica y verdadera del amor filial que es el respeto y el amor "sin ternura".

Lanza es también otra situación límite, como si en la novela se afirmara que la vejez o la edad no se oponen a los ideales renovados. Lanza tiene fe en los hombres y en si mismo, y a través de estas cualidades se autentifica permanen'emente. Ahora podemos afirmar que el mismo dualismo por oposición ya señalado entre Larsen y Antón Bergner se manifiesta entre Ianza y el padre de Jorge. Mientras que Lanza es un padre funcional, el dueño del periódico El Liberal es solamente un padre nominal. Uno tiene para Jorge paternidad auténtica, y el otro sólo representa el papel de padre frente a la sociedad.

El último capítulo de Juntacadáveres merece una atención especial. Aquí lo clasificamos como epílogo para la novela peto posee carácter sumario porque en él queda sintetizado Jorge y además está contenida una escena artísticamente estilizada que es la del entierro de Julita. Esta escena, narrada por Jorge en primera persona, nos enfrenta otra vez con esa dicotomía de los opuestos que hemos venido señalando. $\mathrm{L}_{a}$ oposición aparece ahora en la visión última de Julita que brota con una dimensión simbólica. El suicidio de ésta, último desafío y póstuma acusación a la comunidad sanmariana, redime a Jorge frente a sí mismo. Sin poder negarse a sí misma, Julita elige el suicidio como evasión final y definitiva. En la cínica complicidad del complot de la mutua conveniencia, los triunfadores del mundo son generalmente los que renuncian a su antenticidad; toda la vida entera es para ellos pero no el minuto de vida. Julita los deja a ellos con su bello mundo. Esta dimensión de Julita-símbolo coincide con la visión superrealista de Jorge y de esta forma llega a decirnos que: "Todo era un sueño" (p. 254).

La verdad, la experiencia revitalizadora de Jorge en esie momento es Julita muerta, colgada de una viga. La verdad, la única verdad, la verdad subjetiva, es el encuentro con esa visión de la muerte que es Julita. Todo lo demás, "todo era un sueño": el entierro burgués y conformista, el padre de Jorge, y la madre rodeada de "varonas fuertes" (p. 253) ; Marcos babeando su "corta entrega espiritual de un borracho" (p. 253); el cura, "terco, de espaldas a todo" (p. 255); y finalmen'e "las heredadas frases moscas" (p. 255). 
La experiencia simbólica de Jorge queda condensada en lo siguiente: "Sólo ella (Julita) podía ver cómo me alejaba para bajar, sin remedio, hacia un mundo normal y astuto" (p. 256).

La adolescencia pertenece al pasado, Jorge ha completado su edu. cación sentimental, ese "mundo normal y astuto" es el mundo adulto en el que Jorge seguirá viviendo solo, sin Julita, en medio de ese rechazo sin compromisos que ha elegido libremente.

Albert de la Fuente

Soutbwestem University, Georgetown, Texas 
